EXTENDED REPORT

\title{
Impaired elastic properties of ascending aorta in patients with giant cell arteritis
}

\author{
P N Margos, I E Moyssakis, A G Tzioufas, E Zintzaras, H M Moutsopoulos
}

See end of article for authors' affiliations .......................

Correspondence to: Professor Haralampos $M$ Moutsopoulos, Department of Pathophysiology, Medical School, National University of Athens, $75 \mathrm{M}$ Asias St, Goudi, 11527 Athens, Greece hmoutsop@med.voa.gr

Accepted 20 June 2004 Published Online First 1 July 2004
Objective: To investigate the elastic properties of the ascending aorta in untreated patients with giant cell arteritis compared with age and sex matched normal controls.

Methods: Distensibility of the ascending aorta and aortic strain were measured in 22 patients with a recent diagnosis of giant cell arteritis (documented by a positive temporal artery biopsy) before initiation corticosteroid treatment, and in 44 age and sex matched healthy subjects. Aortic distensibility was calculated as $2 \times$ [pulsatile change in aortic diameter]/[(diastolic aortic diameter) $\times$ (aortic pulse pressure)], and aortic strain as [pulsatile change in aortic diameter]/[diastolic aortic diameter]. Aortic diameters were measured by echocardiography. Aortic pressures were obtained by external sphygmomanometry.

Results: Distensibility of the ascending aorta and aortic strain were both lower in patients with giant cell arteritis than in the controls $(p<0.01)$. In the patients with giant cell arteritis, aortic distensibility was inversely correlated with white blood cell count $(p<0.05)$, but not with erythrocyte sedimentation rate or $C$ reactive protein.

Conclusions: Compared with healthy subjects, aortic distensibility and aortic strain are decreased in patients with giant cell arteritis before initiation of corticosteroid treatment. There was an association between the degree of reduction of aortic distensibility and the white blood cell count in the patient group.
G iant cell arteritis, also referred as temporal arteritis, cranial arteritis, or granulomatous arteritis, is an inflammatory arterial disease which most prominently involves the cranial branches of the arteries originating from the aortic arch. ${ }^{1}$ Patients are almost always over 50 years of age at the time of diagnosis, ${ }^{23}$ the mean age being 70 years. The symptoms of the disease are related to the affected arteries. ${ }^{12}$ The American College of Rheumatology (ACR) has formulated criteria for the classification of giant cell arteritis. ${ }^{14}$ Corticosteroids are the drugs of choice for treatment in patients with this condition.

The implications for the heart and ascending aorta in patients with giant cell arteritis are more serious than might be expected. ${ }^{5}$ The most common clinical presentations are coronary ischaemia, ${ }^{6}$ dilatation of the ascending aorta, aortic regurgitation, and aortic dissection. ${ }^{7-9}$ The inflammatory process weakens the aortic wall, and fragmentation of the elastic fibres has been observed. ${ }^{10}$

Several conditions and diseases such as old age, coronary artery disease, congestive heart failure, arterial hypertension, diabetes mellitus, chronic renal failure, Marfan's syndrome, smoking, and severe aortic regurgitation may cause alterations in the physical properties of the aorta, resulting in increased rigidity and impaired aortic distensibility. ${ }^{11}$

Aortic distensibility can be measured from the changes in aortic diameter and pulse pressure ${ }^{11}$ using invasive and noninvasive techniques. ${ }^{12-14}$

Our aim in this study was to investigate the elastic properties of the ascending aorta (aortic distensibility and aortic strain) in patients with giant cell arteritis before the initiation of corticosteroid treatment. To do this we compared a group of affected patients with a group of healthy controls. We also examined the possible correlation between the degree of reduction of aortic distensibility or aortic strain and the presence of inflammatory markers in the patient group.

\section{METHODS}

Study population

Subjects for the study were 22 sequential patients first seen between May 2001 and December 2003 with a recent diagnosis of giant cell arteritis. The diagnosis was in accordance with the ACR criteria for the disease, and was confirmed by a biopsy of the temporal artery before treatment with corticosteroids was begun. We also recruited 44 healthy controls matched for age and sex. Patients with a history of coronary heart disease or cerebrovascular events, moderate or severe arterial hypertension (or receiving antihypertensive drugs), diabetes mellitus, moderate or severe aortic regurgitation, Marfan's syndrome, chronic renal failure, or congestive heart failure were excluded. There were no differences between the two groups in the use of statins or other drugs that could influence endothelial function.

The groups were compared for the two primary outcomes, aortic distensibility and aortic strain, and for several secondary outcomes: mild aortic regurgitation, left ventricular ejection fraction, aortic root diameter, ascending aorta diameter, systolic blood pressure (SBP), diastolic blood pressure (DBP), and heart rate. In addition, for the group of patients with giant cell arteritis, we investigated the association between the primary outcomes and a selection of inflammatory markers (erythrocyte sedimentation rate (ESR), white blood cell count (WBC), packed cell volume (PCV), C reactive protein concentration, and duration of symptoms before the diagnosis).

\section{Procedures}

Blood examinations

Blood samples were taken from all patients with giant cell arteritis. Common haematological and inflammatory markers (PCV, WBC, ESR, and C reactive protein) were analysed.

Abbreviations: $A C R$, American College of Rheumatology; BMil, body mass index; DBP, diastolic blood pressure; SBP, systolic blood pressure 


\section{Echocardiographic study}

A comprehensive echocardiographic examination was done using a Hewlett Packard Sonos 1000 ultrasound system with a $2.5 \mathrm{MHz}$ transducer. From the cross sectional, four chamber view the ejection fraction of the left ventricle was calculated using Simpson's rule. Aortic valve structure and function were examined using the Doppler method, beginning with colour flow imaging. When abnormal intracardiac flow was detected, pulsed and continuous wave Doppler studies were done. Regurgitation severity grading was semiquantitative and was based on the size and duration of the transvalvar jet. ${ }^{15}$ Measurements of diastolic and systolic diameter of the ascending aorta and aortic root were record at a level $3 \mathrm{~cm}$ above the aortic valve and at the aortic orifice, respectively, guided by $\mathrm{M}$ mode tracking using cross sectional echocardiography in the parasternal long axis view. Systolic and diastolic aortic diameters were measured at maximum anterior motion of the aorta and at the peak of the QRS complex, respectively.

The intraobserver and interobserver mean percentage error (absolute difference between two observations divided by the mean, expressed as a percentage) was determined for the aortic dimensions in 20 randomly selected subjects. The values were $4.2 \%$ and $4.6 \%$ for the systolic dimension and $4.1 \%$ and $4.4 \%$ for the diastolic dimension, respectively, in our centre.

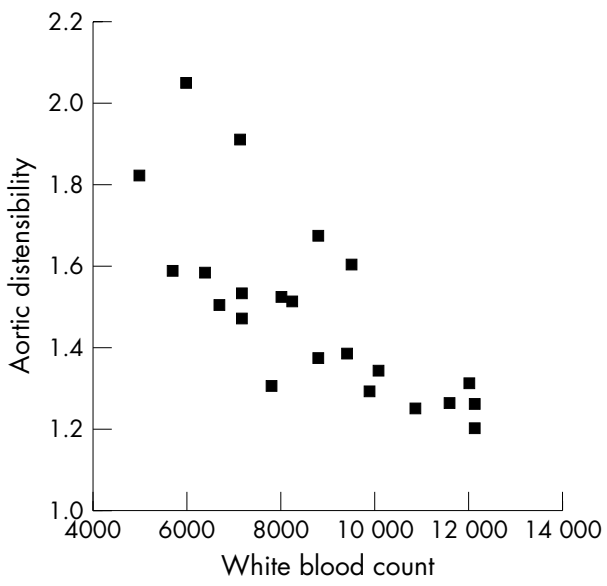

Figure 1 Scatterplot of the association between aortic distensibility and white blood cell count $(p<0.05)$.

Blood pressure was measured with an external sphygmomanometer. Brachial artery pressures (systolic and phase $\mathrm{V}$ diastolic) were determined before and after the echocardiographic study and the mean of the pressures was used in subsequent calculations.

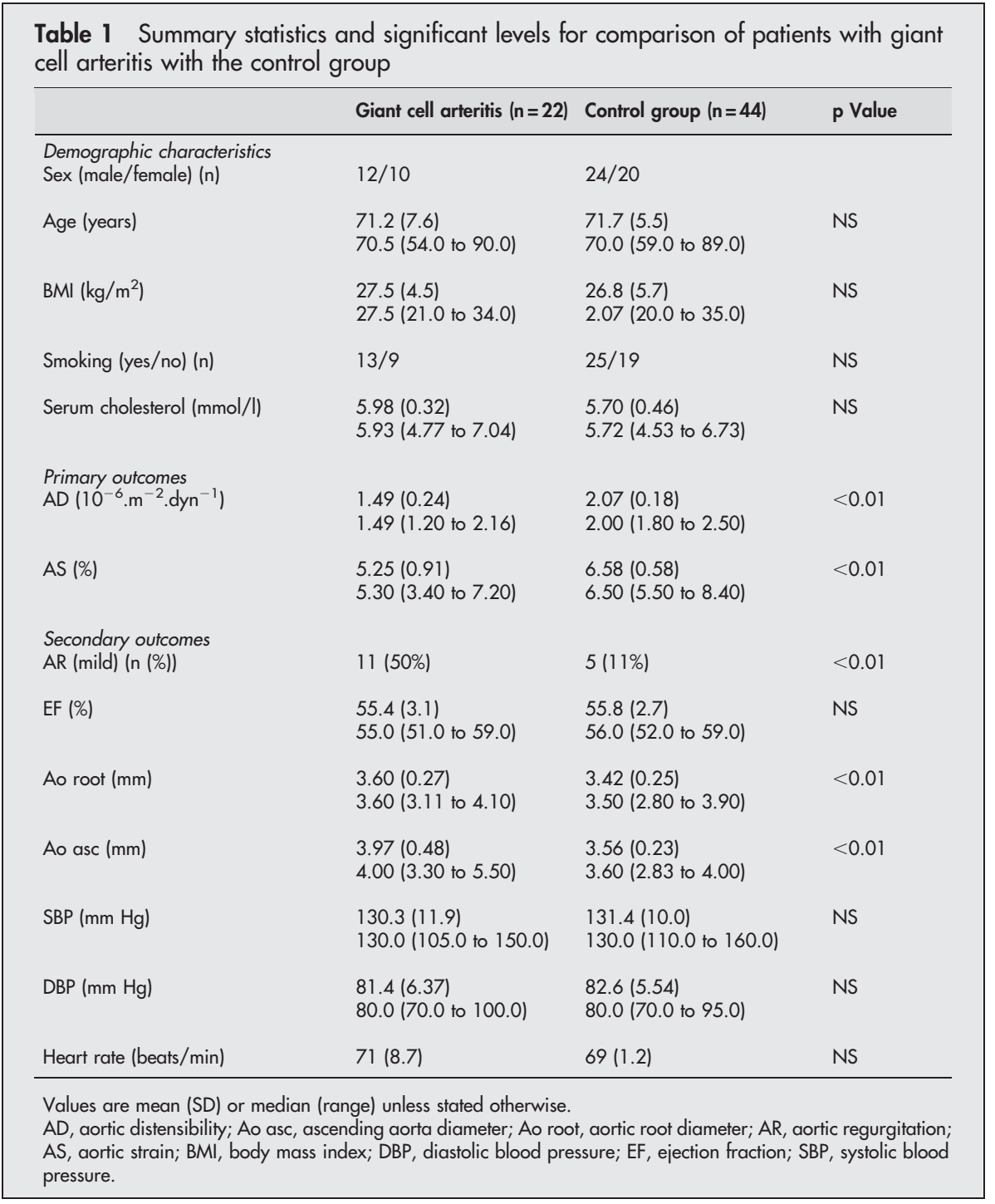


Calculation of aortic distensibility and aortic strain The distensibility of the ascending aorta was calculated from the pulsatile changes of the echocardiographic aortic diameters and pulsatile changes of aortic pressure, using the formula:

aortic distensibility $=2 \times$ pulsatile change in aortic diameter $] /[$ (diastolic aortic diameter $) \times($ aortic pulse pressure)],

where pulsatile change in aortic diameter $=$ systolic - diastolic aortic diameter, and aortic pulse pressure $=$ systolic - diastolic blood pressure.

Aortic strain, expressed as percentage change, was calculated using the formula:

aortic strain $=$ [pulsatile change in aortic diameter $]$ / [diastolic aortic diameter].

\section{Statistical analysis}

The differences in the primary outcomes (aortic distensibility and aortic strain), in the secondary outcomes (aortic regurgitation, ejection fraction, aortic root diameter, ascending aorta diameter, SBP, DBP, and heart rate), and in age, body mass index (BMI), and serum cholesterol between the patient and control groups were investigated using the nonparametric Mann-Whitney U test. The two groups were also compared overall, combining the two primary outcomes, using bivariate analysis of variance. The two groups were compared for the aortic regurgitation variable and smoking status using a $\chi^{2}$ test. In addition, the group effect and the interaction between group differences and the aortic regurgitation effect were compared for each primary outcome using a general linear model.

For the patient group, we investigated the association between aortic distensibility or aortic strain and the inflammatory markers ESR, WBC, PCV, C reactive protein, and duration of symptoms before diagnosis by fitting two multiple linear regression models. In this model, the response was the primary outcome and the explanatory variables were the inflammatory indices. The effects were considered significant at a probability ( $p$ ) value of $<0.05$. The analyses were done using SPSS r.11 statistical software.

\section{RESULTS}

No differences in demographic variables and other characteristics (BMI, smoking status, cholesterol level, blood pressure, heart rate, or left ventricular ejection fraction) were observed between the two groups. Patients with giant cell arteritis had significantly reduced aortic distensibility compared with the healthy age and sex matched controls (mean (SD): 1.49 (0.24) v $\left.2.07(0.18) \times 10^{-6} \cdot \mathrm{m}^{-2} \cdot \mathrm{dyn}^{-1}, \mathrm{p}<0.01\right)$. Aortic strain

Table 2 Summary statistics of the inflammatory indices and regression coefficients (b) for the association between the inflammatory markers and the primary outcomes in the patient group

\begin{tabular}{llll}
\hline Variables & Mean (SD) & b (AD) & b (AS) \\
\hline Constant & & 2.01 & 3.06 \\
ESR $(\mathrm{mm} / \mathrm{h})$ & $79.0(38.3)$ & $1.10 \times 10^{-3}$ & $9.48 \times 10^{-3}$ \\
WBC $\left.(\mu)^{-1}\right)$ & $8662(2178)$ & $-7.57 \times 10^{-5} \dagger$ & $-1.03 \times 10^{-4}$ \\
PCV $(\%)$ & $33.7(4.0)$ & $3.75 \times 10^{-3}$ & $8.14 \times 10^{-2}$ \\
C reactive protein & & & \\
(mg/dl) & $53.6(43.2)$ & $-8.06 \times 10^{-4}$ & $-3.16 \times 10^{-3}$ \\
Duration of disease (m) & $3.4(2.2)$ & $-1.10 \times 10^{-2}$ & $-7.01 \times 10^{-2}$ \\
\hline
\end{tabular}

$\mathrm{tp}<0.05$

$A D$, aortic distensibility; $A S$, aortic strain; ESR, erythrocyte sedimentation rate; $m$, months; PCV, packed cell volume; WBC, white blood cell count. was also reduced in patients with giant cell arteritis $(5.25$ $(0.91) \% \vee 6.58(0.58) \%, \mathrm{p}<0.01)$.

The two groups were significantly different in the following secondary outcomes: aortic regurgitation (mild aortic regurgitation was observed in $50 \%$ of patients $v 11 \%$ of healthy subjects, $\mathbf{p}<0.01$ ), aortic root diameter $(3.60(0.27) v$ $3.42(0.25) \mathrm{mm}, \mathrm{p}<0.01)$, and ascending aorta diameter $(3.97$ $(0.48) v 3.56(0.23) \mathrm{mm}, \mathrm{p}<0.01)$. General linear model analysis showed a difference $(\mathrm{p}<0.01)$ between the groups, but no significant interaction between either group and the aortic regurgitation effect for each primary outcome $(p>0.05)$. There were no significant between group differences in ejection fraction, SBP, DBP, or heart rate (table 1).

With respect to the possible association between aortic distensibility or aortic strain and inflammatory markers (ESR, WBC, PCV, C reactive protein, duration of symptoms before diagnosis), linear regression analysis showed only that aortic distensibility was inversely associated with WBC $(\mathrm{p}<0.05$; table 2, fig 1$)$.

\section{DISCUSSION}

This study shows that, compared with healthy subjects, aortic distensibility and aortic strain are reduced in patients with recent onset giant cell arteritis, before the start of corticosteroid treatment. Some evidenc of a correlation between the degree of impairment of aortic distensibility or aortic strain and inflammatory markers was found-specifically, aortic distensibility was inversely correlated with the white blood cell count $(\mathrm{p}<0.05)$. The incidence of aortic regurgitation or dilatation of the ascending aorta in patients with giant cell arteritis in our study was is in accordance with previous reports. ${ }^{9}$ To our knowledge, this is the first investigation to show alterations in the elastic properties of the ascending aorta in patients with giant cell arteritis.

It is well known that the elastic properties of large arteries are impaired in various conditions, including old age, coronary artery disease, congestive heart failure, arterial hypertension, diabetes mellitus, chronic renal failure, Marfan's syndrome, and severe aortic regurgitation. ${ }^{11}$ It has been reported that aortic distensibility is increased in elite athletes. ${ }^{16}$ There is little published evidence on the relation between rheumatic diseases in general and the elastic properties of large arteries. Decreased distensibility of the large arteries has been reported in patients with systemic sclerosis. ${ }^{17} 18$

Structural changes of the aortic wall or alterations of vasa vasorum flow have been detected in conditions such as arterial hypertension and aging, which involve impairment of the elastic properties of the aorta. ${ }^{19}$ With respect to the pathology of the inflammatory arterial lesions in patients with giant cell arteritis, the prominent finding is that the inflammatory process is usually more apparent in the inner portion of the media, adjacent to the internal elastic lamina ${ }^{1}$ (described as a granulomatous reaction ${ }^{10}$ ). Fragmentation and disintegration of elastic fibres occurs, closely associated with an accumulation of giant cells. ${ }^{1}{ }^{10}$ Elastolysis by multinucleated giant cells has also been reported. ${ }^{20}$ The granulomatous inflammatory reaction in the arterial wall has been observed not only in temporal artery biopsy specimens but also in surgical and necropsy aortic tissue specimens. ${ }^{1021}$ Positron emission tomography has also detected an inflammatory process in the aortic arch. ${ }^{5}$ In fact, most patients with giant cell arteritis appear to have giant cell aortitis at some time. $^{5}$ These observations raise questions about impairment of the elastic properties of the ascending aorta in patients with giant cell arteritis. Although it is difficult to assess structural changes in the intact human aorta, it is relatively easy to assess the elastic properties of the vessel. 
The partial correlation between the degree of impairment of aortic elastic properties and inflammatory markers supports the pathophysiological basis of the lesions, whereby the inflammatory process in the inner portion of the mediaand the resulting fragmentation and disintegration of elastic fibres-is probably responsible for the impaired elastic properties of the ascending aorta in giant cell arteritis.

Our study has some limitations. Aortic diameters were measured echocardiographically and not invasively. A previous study has shown that aortic diameter can be determined with a high degree of accuracy in subjects whose cardiothoracic anatomy permits an echocardiographic signal of satisfactory quality, ${ }^{13}$ and the values obtained by echocardiography were not significantly different from those obtained by angiography. ${ }^{13}$ In our study we had no difficulty in obtaining an echocardiographic signal of good quality. In addition, pulse pressure estimated non-invasively from the brachial artery by external sphygmomanometry has been shown to correlate well with that measured directly from the aorta and has been used for the calculation of aortic distensibility in previous reports. ${ }^{13}{ }^{22-24}$ Although this noninvasive technique introduces an error factor ${ }^{22}$ owing to slight amplification of pulse pressure at more distal arterial sites, its final effect on the validity of the distensibility calculation is trivial. These non-invasive techniques have also been used for calculating aortic distensibility in previous studies..$^{23-25}$ Thus a reliable estimation of the elastic properties of the ascending aorta using completely non-invasive techniques is feasible.

\section{Conclusions}

Structural and molecular changes of the aortic wall in patients with giant cell arteritis may be responsible for a reduction in the elastic properties of the ascending aorta. An increase in the number of patients examined would clarify the inverse correlation between the impaired elastic properties of the ascending aorta and inflammatory marker positivity.

\section{Authors' affiliations}

P N Margos, A G Tzioufas, H M Moutsopoulos, Department of Pathophysiology, University of Athens Medical School, Greece I E Moyssakis, Department of Cardiology, Laikon University Hospital of Athens, Greece

E Zintzaras, Department of Biomathematics, University of Thessaly Medical School, Greece

\section{REFERENCES}

1 Kelly W, Harris E, Ruddy S, Sledge C. In: Textbook of rheumatology, 4th ed. Philadelphia: WB Saunders, 1993:1103-12.

2 Weyand CM, Coronzy JJ. Giant cell arteritis and polymyalgia rheumatica. Ann Intern Med 2003;139:505-15.

3 Machado EB, Michet CJ, Ballard DJ, Hunder GG, Beard CM, Chu CP, et al. Trends in incidence and clinical presentation of temporal arteritis in Olmsted County, Minnesota, 1950-1985. Arthritis Rheum 1988;31:745-9.
4 Hunder GG, Bloch DA, Michel BA, Stevens MB, Arend WP, Calabrese LH, et al. The American College of Rheumatology 1990 criteria for the classification of giant cell arteritis. Arthritis Rheum 1990;33:1122-8.

5 Blockmans D, Stroobants S, Maes A, Mortelmans L. Positron emission tomography in giant cell arteritis and polymyalgia rheumatica: evidence for inflammation of the aortic arch. Am J Med 2000;108:246-9.

6 Kumar P, Velissaris T, Sheppard MN, Pepper JR. Giant cell arteritis confined to intramural coronary arteries. Unforeseen hazards myocardial protection. J Cardiovasc Surg (Torino) 2002;43:647-9.

7 Nuenninghoff DM, Hunder GG, Christianson TJ, McClelland RL, Matteson EL. Mortality of large artery complication (aortic aneurysm, aortic dissection and/ or large artery stenosis) in patients with giant cell arteritis. Arthritis Rheum 2003;48:3532-7.

8 Nuenninghoff DM, Hunder GG, Christianson TJ, McClelland RL, Matteson EL. Incidence and predictors of large-artery complication (aortic aneurysm, aortic dissection and/or large artery stenosis) in patients with giant cell arteritis. Arthritis Rheum 2003;48:3522-31.

9 Evans JM, O'Fallon WM, Hunder GG. Increased incidence of aortic aneurysm and dissection in giant cell (temporal) arteritis: a population based study. Ann Intern Med 1995;122:502-7.

10 Petursdottir V, Nordborg E, Nordborg C. Atrophy of the aortic media in giant cell arteritis. APMIS 1996;104:191-8.

11 Benetos A, Waeber B, Izzo J, Mitchell G, Resnick L, Asmar R, et al. Influence of age, risk factors and cardiovascular and renal disease on arterial stiffness: clinical applications. Am J Hypertens 2002;15:1101-8.

12 Stefanadis C, Wooley CF, Bush CA, Kolibash AJ, Boudoulas H. Aortic distensibility in post-stenotic aortic dilatation: the effect of co-existing coronary artery disease. J Cardiol 1988;18:189-95.

13 Stefanadis C, Stratos C, Boudoulas H, Kourouklis C, Toutouzas P. Distensibility of the ascending aorta: comparison of invasive and non-invasive techniques in healthy men and in men with coronary artery disease. Eur Heart $J$ 1990;11:990-6.

14 Mohiadin RH, Underwood SR, Borgen HG, Firmin DN, Klipstein RH, Rees RS, et al. Regional aortic compliance studied by magnetic resonance imaging: the effects of age, training and coronary artery disease. Br Heart $J$ 1989:62:90-6.

15 Otto CM. In: Textbook of clinical echocardiography, 2nd ed. Philadelphia: WB Saunders, 2000:280-5.

16 Erol MK, Yilmaz M, Oztasyonar Y, Sevimli S, Senokac H. Aortic distensibility is increased in elite athletes. Am J Cardiol 2002;89:1002-4.

17 Constans J, Gosse P, Pellegrin JL, Ansoborlo P, Leng B, Clementy J, et al. Alterations of arterial distensibility in systemic sclerosis. J Intern Med 1997;241:115-18.

18 Gosse P, Taillard J, Constans J, on behalf of the ERAMS study investigators. Evolution of ambulatory measurement of blood pressure and parameters of arterial stiffness over a 1-year period in patients with systemic sclerosis: ERAMS study. J Hum Hypertens 2002; 16:627-30.

19 Marcus ML, Heistad DD, Armstrong ML, Abbound FM. Effects of chronic hypertension on vasa vasorum in the thoracic aorta. Cardiovasc Res 1985; 19:777-81.

20 Gillot JM, Masy E, Davril M, Hachulla E, Harton PY, Devulder B, et al. Elastase derived elastin peptides: putative autoimmune targets in giant cell arteritis. J Rheumatol 1997;24:677-82.

21 Lie JT, Failoni DD, Davis DC. Temporal arteritis with giant cell aortitis, coronary arteritis, and myocardial infarction. Arch Pathol Lab Med 1986;110:857-60.

22 Gatzka CD, Cameron JD, Kingwell BA, Dart AM. Relation between coronary artery disease, aortic stiffness, and left ventricular structure in a population sample. Hypertension 1998;32:575-8.

23 Dart AM, Lacombe F, Yeoh KJ, Cameron JD, Jennings GL, Laufer E, et al. Aortic distensibility in patients with isolated hypercholesterolaemia, coronary artery disease, or cardiac transplant. Lancet 1991;338:270-3.

24 Eren M, Gorgulu S, Uslu N, Celik S, Dagdeviren B, Tezel T. Relation between aortic stiffness and left ventricular diastolic function in patients with hypertension, diabetes or both. Heart 2004;90:37-43.

25 Lacombe F, Dart A, Dewar E, Jennings G, Cameron J, Laufer E. Arterial elastic properties in man: a comparison of echo-Doppler indices of aortic stiffness. Eur Heart J 1992;13:1040-5. 